\title{
A INTERPRETAÇÃO DO PROSLOGION POR KARL BARTH
}

Paulo Ricardo MARTINES ${ }^{1}$

- RESUMO: O objetivo principal deste texto é apresentar alguns elementos essenciais da interpretação do Proslogion feita por Karl Barth em seu livro S. Anselme, Fides Quaerens Intellectum. La preuve de l'existence de Dieu (trad. franc.). Com Base no "programa teológico" de Anselmo, Barth identifica as linhas fundamentais para a leitura dos capítulos 2 a 4 do Proslogion. Tentaremos mostrar a significação e o alcance dessa interpretação para a historiografia do pensamento anselmiano.

- PALAVRAS-CHAVE: Anselmo; argumento ontológico; existência; essência.

O objetivo principal deste trabalho² é apresentar alguns elementos essenciais da interpretação do Proslogion feita por Karl Barth. O teólogo protestante publica no início da década de 1930 uma obra intitulada S. Anselme, Fides Quaerens Intellectum. La preuve de l'existence de Dieu. ${ }^{3}$ A análise minuciosa de Barth limita-se aos pequenos capítulos 2 a 4, nos quais Anselmo procurou desenvolver a sua argumentação acerca do problema da existência de Deus.

Esse pequeno conjunto de capítulos do Proslogion passou para a história da filosofia como possuindo a forma e o conteúdo de um argumento ontológico, denominação esta dada por Kant (aliás, seu adversário) na Crítica da razão pura. ${ }^{4}$ Esse argumento fez fortuna na história da filosofia. Hegel procura identificar a prova anselmiana com a idéia do perfeito:

ela constitui o fundamento abstrato, metafísico desse grau (isto é, o puro conceito); ela foi descoberta em primeiro lugar no cristianismo por Anselmo de Cantuária. Ela é exposta em seguida

1 Mestre em Filosofia - Pontifícia Universidade Católica - São Paulo - SP.

2 Comunicação apresentada na VI Anpof (Águas de Lindóia - 1994).

3 Utilizamos a edição francesa publicada pela editora Labor et Fides, 1985 - tradução de Jean Corrèze. Como não foi possivel obter o original alemão, conferimos sempre essa tradução com a inglesa, de I. W. Robertson, Cleveland, The World Publishing, 1960.

4 “Dialética transcendental, cap.III, 4ª seção, da obra Crítica da razão pura, de I. Kant. 
por todos os filosófos posteriores, Descartes, Leibniz, Wolff, entretanto, sempre ao lado de outras provas, se bem que ela seja a única prova verdadeira. (1947, p.242)

Em linhas gerais, a prova ontológica pressupõe a idéia de Deus presente no intelecto, e daí afirma necessariamente a existência como uma perfeição do ser supremo.

Entretanto, devemos fazer duas observações quanto à utilização dessa denominação para o texto do Proslogion. Em primeiro lugar, não podemos atribuir a Anselmo nenhum quadro ou esquema conceitual que não pertença ao universo de sua análise. Anselmo é um pensador do século XI, que pertence inteiramente ao universo agostiniano; em termos históricos, estamos nos primórdios da Escolástica. Em segundo, o epíteto prova ou argumento ontológico é empregado com mais rigor quando referido a Descartes, principalmente às suas terceira e quinta Meditações, ao conceber a idéia do perfeito. Exemplo mais evidente ainda pode ser extraído do texto das Premières réponses:

Mais mon argument a été tel: ce que nous concevons clairement et distinctement appartenir à la nature, ou à l'essence, ou à la forme immuable et vraie de quelque chose, cela peut être dit ou affirmé avec vénité de cette chose; mais après que nous avons assez soigneusement recherché ce que c'est que Dieu, nous concevons clairement et distinctement qu'il appartient à la vraie et immuable nature qu'il existe; donc alors nous pouvons affirmer avec vérité qu'il existe. Ou du moins la conclusion est légitime. (1967, t.I, p.534-5)

Assim, Descartes afirma que a necessidade da idéia de Deus não é dada por nenhuma medida subjetiva.

Devemos destacar que o estudo de Barth foi o primeiro a considerar o próprio texto de Anselmo. Todos aqueles que faziam referência ao argumento, faziam-no por outras vias que as do "Doutor Magnífico".

Devemos ressaltar, ainda, que o interesse pela obra de Barth se dá, em primeiro lugar, pela importância que assume na historiografia anselmiana; em segundo, pelo rigor de análise e pelo horizonte de informações que nos fornece. Isso, entretanto, não nos autoriza a compartilhar todas as conclusões a que chega o insigne crítico.

Antes de considerarmos os principais elementos da análise de Barth, convém apresentarmos sucintamente o horizonte intelectual de seu pensamento.

O teólogo suíço insere-se numa orientação intelectual (religiosa) de uma fé que busca a compreensão: o crer individual subjetivo supõe o credo objetivo. A proposta de Barth é procurar, em todos assuntos relacionados à fé, uma necessidade interior tal como manifestada na revelação, ou seja, procurar uma objetividade estritamente teológica. Sua Dogmática, a grande obra que empreendeu durante anos, é, nas palavras de Vignaux: "un essai de théologie radicalement pure de tout jugement philosophique" (1973, p.88). Sua posição sobre o problema do conhecimento de Deus manifesta-se de uma forma radical: só temos, diz, uma única fonte: a revelação judaicocristã. Está excluída, portanto, toda e qualquer tentativa de teodicéia. Barth tinha o 
interesse de arrancar o argumento ontológico do monopólio da filosofia e restituí-lo ao seu verdadeiro lugar: a teologia. A relação entre razão e fé não se torna propriamente um problema dentro das teologias protestantes. Neste sentido, afirma Gilson: "il s'agit évidemment de soumettre la raison à la foi ou, plus exactement encore, d'interdire à la raison de parler d'autre langage que celui de la foi" (1949, p.44).

Para Barth, o argumento ontológico é válido somente na teologia. O teólogo protestante rejeita qualquer prova acerca da existência de Deus; considera ilegítimas todas as tentativas. O que sustenta tal pressuposto de Barth? A tese de que o homem é incapaz de alcançar o conhecimento de Deus, do verdadeiro Deus. O homem não prova Deus. Na sua tentativa de possuir determinado conhecimento especulativo sobre Deus, o homem não produziria mais do que falsos ídolos, projeções do espírito humano que não teriam nada de comum com o Deus que se manifesta na tradição judaico-cristã. Barth (1985) tem presente, nesse momento, parece-nos, uma passagem de São Paulo (Romanos 1, 22) sobre os homens que não souberam honrar o Deus criador: "Jactando-se de possuir a sabedoria, tornaram-se tolos e trocaram a glória do Deus incorruptível por imagens do homem corruptível".

Para Barth, a única prova humana possível é a prova teológica. Do ponto de vista da palavra de Deus, ela é legítima, porque não se distingue da prova que Deus dá de si mesmo na revelação. Desse modo, a prova teológica limita-se a repetir soletrando essa autodemonstração de Deus (cf. Delhougne, 1979, p.49). Nesse sentido, a única prova do pensamento ocidental seguidora desse modelo é a prova desenvolvida por Anselmo.

Das considerações feitas até o momento, podemos afirmar que o estudo de Barth é importante por um triplo ponto de vista:

1 Expõe a concepção barthiana do problema da existência de Deus.

2 Renova a interpretação do argumento de Anselmo.

3 Constitui, como disse Bouillard (1957, t.I, p.145), o "discurso do método" de Barth.

Destes três aspectos, interessa-nos apenas e tão-somente o segundo, que apresenta as considerações sobre o argumento de Anselmo, ficando os demais para o interesse dos teólogos. O texto de Barth divide-se em duas partes:

a) a exposição do programa teológico de Anselmo e

b) a exposição da prova da existência de Deus.

O nosso objetivo básico limita-se a definir o ato do intelligere, pois este é a peça central de toda a interpretação barthiana. Vamos considerar o programa teológico de Anselmo tal como entende Barth, e verificar como o argumento único insere-se neste programa.

Barth está convencido de que os três pequenos capítulos do Proslogion têm por finalidade provar a existência de Deus. Cita em sua defesa uma passagem da resposta de Anselmo a Gaunilo: "Julgo ter mostrado que, no livro acima [Proslogion], 
eu provei por uma argumentação não infirme, mas suficientemente necessária, que existe na própria coisa algo tal que nada de maior pode ser pensado" . ${ }^{5}$ Devemos sublinhar a palavra provar (probare), pois, na interpretação que Barth faz do vocabulário anselmiano, este verbo possuirá um sentido muito específico, distante de qualquer conotação lógica. O provar só poderá ser entendido dentro de um movimento próprio que é aquele do intelligere (Barth traduz por compreender), que, por sua vez, se dá no interior da fé.

O desejo de compreender aquilo que se crê nasce do próprio domínio da fé: a procura do conhecimento é imanente à fé. O credo ut intelligam, de origem agostiniana, foi assim traduzido por Barth: "minha fé, ela mesma enquanto tal, é um apelo ao conhecimento" (1985, p.16). A fé, para Anselmo, só pode ser entendida como tal se for uma fé viva (fides viva). Essa fé caracteriza-se essencialmente pela presença do amor e consiste em crer naquilo em que se deve crer. Em contraposição a esse tipo de fé, existe a fé morta (fides mortua) que não possui a presença do amor, é inoperante, caracterizando-se pela falta de interesse. A fé como condição prévia a todo estudo teológico parece ser o ponto central da primeira parte do livro de Barth.

Quatro aspectos caracterizam a exigência da anterioridade da fé que se traduz no ato do intelligere: 1) Deus não é apenas a verdade soberana, mas causa da verdade (causa veritatis), nas palavras de Anselmo "Cremos que Deus é a verdade";6 2) a fé é um movimento da vontade: o tendere in deum é uma decisão livre para se harmonizar com o criador; 3) o homem é imago dei: graças a isso é capaz de: lembrar, conhecer e amar; e 4) a forma escatológica: o conhecimento que adquirimos nesta vida é algo de intermediário entre a fé e a visão beatífica (definição de Anselmo presente na Epistola Incarnatione Verbi). Para Barth (1985, p.18), é precisamente na procura (quaerere) e na conseqüente descoberta (invenire) que a inteligência se vê nos limites inexoráveis da humanidade. Dessa forma, o cristão deve distinguir, com uma dolorosa clareza, aquilo que é inteligível para ele, daquilo que é do próprio Deus.

A fé exige e torna possível o conhecimento que o cristão busca. Desse postulado, podemos tirar algumas conseqüências para o exercício do trabalho teológico que serão fundamentais para Barth justificar sua interpretação.

A fé refere-se de início ao credo; daí o conhecimento da fé ser continuação e explicação (não justificação) do credo. O cristão que procura a inteligência da fé não coloca em dúvida qualquer proposição referente ao credo; apresenta, por outro lado, a questão do "como" pode ocorrer, por exemplo, a negação de determinada proposição do credo. É tarefa do teólogo, diz Barth (p.25), procurar humildemente, enquanto puder, a razão do "como" determinado artigo de fé apresenta-se com tal ordem de inteligibilidade, pois "toda continuação, toda explicação, toda meditação do credo

5 "Puto quia mostraui me non infirma sed satis necessana argumentatione probasse in praefato libello re ipsa existere aliquid quo maius cogitari non possit". "Contra Gaunilonem", in S. Anselmi Cantuariensis Archiepiscopi, 19461951, cap.10, p.138, 28-30. (doravante SA).

6 "De Veritate", in SA, 1946-1951, cap.I, p.176, 1. 
afirmada pela fé não pode ser mais do que um comentário do credo". Essa procura da inteligência da fé aponta um limite: a possibilidade de compreender racionalmente que a substância suprema é incompreensível; ultrapassar esse limite é tarefa apenas do insensato.

Aspecto fundamental nas reflexões de Barth sobre o intellectus fidei (inteligência da fé) é o papel assumido pela graça divina: o homem na sua condição atual (de miserável e pecador) não pode alcançar a ratio veritatis (razão da verdade). Essa é muito ampla para ele, pois, por mais que se esforce, seu pensamento (como fala) é insuficiente para atingir a perfeição divina; por isso "o senhor dispensará os dons de sua graça" (p.28). O homem pode atingir um certo progresso teológico, determinado pela sabedoria de Deus. Para Anselmo, o verdadeiro conhecimento, diz Barth, é alcançado pela graça proveniente de Deus. É neste sentido que deve ser entendido o papel da prece do Proslogion: uma invocação a Deus.

Nessa prece, Anselmo procura caracterizar (numa linguagem de rara beleza poética) o estado do homem que crê e deseja ver o Deus de sua Fé, mas está distanciado deste pelo pecado. O homem pertencente à humanidade adâmica faz um apelo para Deus ensinar ao seu coração como e onde procurá-lo. Diz Barth: "Toda verdadeira procura de Deus (e isto também é uma graça) não serviria para nada se Deus não se mostrasse, ou, em outras palavras, o verdadeiro conhecimento não se tornaria um acontecimento" (p.35).

Definida a natureza da fé e, em certa medida, os limites do trabalho teológico, podemos apresentar uma primeira definição do ato do intelligere: "a capacidade de repensar aquilo que já foi dito no credo" (p.36). O intelligere deve ser entendido no seu sentido etimológico: o de intus + legere: ler dentro. Diante das Escrituras, devemos "penetrar humanamente naquilo que nos foi dado divinamente" (p.37). O teólogo suiço sugere que tal movimento não deve invocar um artigo de fé - alcançado pela simples leitura - mas ultrapassar essa leitura, reconstruir "tábula rasa o credo, com elementos novos" (p.39), que, na perspectiva de Anselmo, é sola ratione (somente com a razão). Essa perspectiva de análise, se assim podemos chamar, é utilizada até para as questões da Trindade, Encarnação e da Redenção; o que, a partir do século XIII, certamente seria impossível para um teólogo.

A expressão sola ratione notabilizou Anselmo, fazendo muitos o considerarem um racionalista. Mas não é neste sentido que devemos entendê-lo. Uma passagem muito esclarecedora do Monologion ${ }^{7}$ dá a medida exata do conceito: ratio é aquilo que pertence ao próprio homem, da mesma forma que afirmamos que o homem é um ser racional: é, com mais precisão, a faculdade de formar julgamentos, de distinguir o verdadeiro do falso (de afirmar que aquilo que é, é; e aquilo que não é, não é). A ratio não pretende deduzir verdades reveladas de premissas humanas. Toda ratio pressupõe a autoridade. Barth ainda identifica em Anselmo (embora reconheça que

7 "Monologion", in: S. A.,1946-1951, cap.68, p.78, 21-3 
o "Doutor Magnífico" nunca utilizou tais termos) três tipos de "razão": a razão noética, que é a faculdade humana do conhecimento, como vimos acima; a razão ontológica, que é a ratio interior ao objeto de fé; e a razão da verdade, que é idêntica ao verbo divino. Esta é pressuposta para a existência das duas primeiras.

Admitindo os elementos fornecidos até aqui por Barth - a idéia de uma fé viva, os limites do trabalho teológico e o uso da expressão sola ratione -, podemos perguntar em que medida a inteligência da fé é verdadeiramente progressão do menos conhecido para o mais conhecido. Para o teólogo suíço, não há dúvida de que a reflexão teológica instaura um acréscimo àquilo já admitido pela fé, principalmente ao fazer aparecer (pelo do movimento do intelligere) a necessidade das razões dos artigos de fé. Trata-se, isto sim, de encontrar a necessidade que é inerente à fé. Este movimento do intelligere assemelha-se à resolução de uma equação (que é um artigo de fé) a partir de outros artigos de fé. Podemos exemplificar esquematicamente: para equacionar um certo artigo de fé $x$ (negado ou colocado em dúvida), recorre-se a outros artigos de fé (a, b, c, d... ). O exemplo de Barth é aquele do Cur Deus Homo. O objetivo dessa obra é mostrar a necessidade interna da encarnação e da morte redentora do Cristo ( nosso $x$ a equacionar) a partir de outros artigos de fé: a existência de um plano divino para o gênero humano, o pecado, a incapacidade do homem salvar-se por si mesmo. Esses elementos $(a, b, c)$ permitem deduzir $o x$, que é a encamação redentora. O objetivo, assim, é apresentar certa inteligibilidade que é própria do artigo de fé, a princípio questionado.

Esse esquema do Cur Deus Homo será aplicado na análise que Barth fará do argumento anselmiano: o que se procura nos capítulos iniciais do Proslogion é mostrar a necessidade interna de um artigo de fé: a existência de Deus a partir de outros artigos.

A passagem do Proslogion em que Anselmo apresenta o argumento único é esta:

Portanto Senhor, tu que concedes a inteligência da fé, conceda-me entender, na medida em que julgues conveniente, que és como cremos e que és o que cremos. Ora, cremos que tu és algo tal que não pode pensar-se nada de maior. (Proslogion, cap.2) ${ }^{8}$

Apenas para mencionar as articulações lógicas que se seguem à aparição da figura do insensato (que nega a existência de Deus), apresentamos resumidamente o raciocínio de Anselmo que conclui pela necessidade da existência de Deus fora da inteligência, isto é, na realidade:

1 O insensato tem na inteligência a expressão "Algo tal que não pode pensar-se nada de maior".

8 "Ergo, domine, qui das fidei intellectum, da mihi ut quantum scis expedire intelligam, quia es sicut credimus, et hoc es quod credimus. Et quidem credimus te esse aliquid quo nihil maius cogitan possit", na obra Opera Omnia (SA, 1946-1951, p.101, 1-3). 
2 Este "Algo tal que não pode pensar-se nada de maior" não pode existir somente na inteligência. Se isso ocorresse, seria possível pensar-se também na coisa, o que é maior.

3 A negação do insensato é absurda e contraditória.

4 Portanto, Deus existe na inteligência e na coisa.

Ora, podemos perguntar com quais artigos de fé Anselmo procurará constituir a inteligibilidade da equação da qual resulta verdadeira a afirmação "Deus existe". Em primeiro lugar, o nome de Deu, "Algo tal que não pode pensar-se nada de maior", é um artigo de fé, revelado, mesmo que não se encontre nas Escrituras. Trata-se menos de um nome do que uma designação, uma definição puramente conceitual, não exprimindo a essência de Deus. É uma designação puramente negativa; nas palavras de Barth, "um conceito puramente noético". Essa designação faz referência apenas a certa regra de pensamento para além da qual o homem não pode aventurar-se. Segundo o esquema barthiano, chamemos essa primeira grandeza de a.

Ao lado dessa grandeza fundamental há outra: a essência de Deus (chamemos de b), que é indispensável para determinar a existência de Deus. É com o auxílio de tal grandeza, diz Barth, que Anselmo poderá afirmar que a existência em questão $(x)$ não é um caso particular da existência em geral (como compreendeu Gaunilo, o seu primeiro contraditor), mas a existência por excelência. São palavras de Barth: "a existência de Deus é, propriamente falando, a existência única e primeira, sobre a qual são fundadas todas as outras existências" (1985, p.45). Temos até aqui que as grandezas $a$ e $b$ são fundamentais para a afirmação da existência necessária de Deus. Mas existem outras grandezas (c, d, e... ) emprestadas também do credo, mas Barth não as indica, deixando assim seu raciocínio inconcluso neste aspecto.

Esse movimento da inteligência que percorre os diversos artigos do credo, confrontando-os para tornar inteligível outro artigo de fé, é, para Barth, o sinal conclusivo de que o argumento anselmiano move-se dentro do terreno da teologia. O teólogo protestante identificou o intellectus fidei como o método de Anselmo.

O ato de provar, já mencionando, pode ser definido com mais precisão agora: provar não significa colocar em questão determinado artigo do credo, mas apresentá-lo relacionado com outros artigos, mostrando argumentativamente aquilo que pela falta de fé é negado. A prova não mostra que tal artigo é verdadeiro, mas sim, como ele o é.

Para Barth, Anselmo não escreveu como um insensato, mas como um católico falando para um insensato: "é verdadeiro que Deus existe, que há um ser em três pessoas ... o que Anselmo discute é a questão de saber como isso é verdadeiro. E quando apresenta a questão do como, que se dá por um artigo de fé, ele responde apoiando-se na verdade, admitida a priori, de todos os outros artigos" (p.55). Barth acrescenta ainda que Anselmo não saiu de seu "campo", não utilizou as armas do insensato. No De Casu Diaboli, obra que pertence a um conjunto de tratados relacionados ao estudo da Sagrada Escritura, o "Doutor Magnífico" comenta: "Nem sempre 
é fácil responder com sabedoria àquele que procura com incipiência". ${ }^{9}$ A oposição apresentada nesta passagem é sabedonia/incipiência: Anselmo procura trazer o insensato para o campo da sabedoria e da racionalidade; seu esforço é aquele de um cristão que procura compreender aquilo que já está afirmado pela fé.

Como conclusão, gostaríamos de fazer duas observações a essa leitura de Barth e, posteriormente, uma objeção em forma de pergunta.

A primeira e mais significativa contribuição de Barth está na identificação e natureza do "nome" que aparece no início do capítulo 2. O "nome" de Deus ("Algo tal que não pode pensar-se nada de maior") é de conteúdo puramente noético e negativo; não diz nada sobre a essência de Deus; mas, antes, assinala uma regra de pensamento para além da qual não podemos formular abolutamente nada, uma hipótese sequer. O que temos é um problema apresentado em novas bases, como diz Paliard: "Dieu ne ressemble à rien, n'appartient à aucun classement intellectuel. C'est tout autrement qu'il faut entendre l'idée de Dieu: non l'essence s'offrant au regard de l'homme mais la désignation de l'essence: aliquid quo nihil maius cogitari non potest" (1946, p.55). Se não for muito arriscado, podemos afirmar que Barth foi o primeiro a romper com a tradição de outorgar ao argumento de Anselmo o epíteto de ontológico. Essa concepção distancia-se da tese essencialista de Gilson (1949), segundo a qual o nome revelado de Deus exprime uma essência, um conteúdo de pensamento; e a análise desse conteúdo basta por si própria para demonstrar a existência de Deus.

A segunda observação é quanto à explicitação do raciocínio per absurdum de Anselmo, enfatizando que não estamos diante de um raciocínio analítico ou sintético. Não existe o menor traço de dedução. Pela análise dos capítulos 2-4, Barth deixa claro que o "método" de Anselmo, amparado no intellectus fidei, é apenas o de fornecer uma releitura dos artigos desconhecidos pelos artigos conhecidos. Em momento algum Barth deixou ressaltar: a orientação do pensamento de Anselmo é puramente teológica; do começo ao fim, a análise do Proslogion se dá no interior da fé. Sofia Vanni-Rovighi (1947, p.49) acredita que essa perspectiva de Barth limita-se mais àquilo que o teólogo protestante considera ser próprio do trabalho teológico do que à própria intenção de Anselmo. O "Doutor Magnífico", segundo a intérprete italiana, ultrapassa a leitura e a simples consideração de relacionar os artigos de fé: procura entendê-los num movimento que é especulativo.

A objeção aponta para a atitude de Anselmo diante da negação do insensato. Como este está desprovido de qualquer elemento de fé, é tarefa vã utilizar a Sagrada Escritura para apontar a não-validade da sua afirmação. A argumentação de Anselmo pauta-se, então, por uma estruturação que tenha pressupostos mínimos de racionalidade, que tenha um sentido independente da presença ou ausência da fé. Anselmo procura trazer (nunca abandonando o terreno da fé) o insensato para o terreno da racionalidade e da sabedoria, que, neste caso, nada mais é do que aceitar a impossibilidade da negação da existência de Deus. Se este pressuposto fosse legítimo, não

9 "Quippe non semper facile est insipienter quaerenti sapienter respondere" ("De Casu Diaboli", in: SA, 1946-1951, cap.28, p.275, 4-5). 
teríamos além do sentido teológico um sentido filosófico, que se caracterizaria pela forma de apresentar e resolver os problemas? Para Henri Bouillard (1959, p.200), a prova anselmiana, na medida em que pertence ao projeto Fides Quaerens Intellectum, não se volta apenas para o interior da fé, mas também para o exterior. O que pode ser verificado pelo fato de ela possuir uma estrutura lógica, e daí ser inteligível para o insensato. A intenção de Anselmo, segundo o prólogo do Proslogion, é provar que Deus existe, e não apenas mostrar como isso é verdadeiro.

MARTINES, P. R. Karl Barth's interpretation of the Proslogion. Trans/Form/Ação (São Paulo), v.19, p.231-239, 1996.

- ABSTRACT: The chief aim of this paper is to present some essential elements of the interpretation to the Proslogion carnied out by Karl Bathr in his book S. Anselme, Fides Quaerens Intellectum. La preuve de l'existence de Dieu (French transl.). Taking Anselm's "theological programme" as a point of departure, Barth indentifies the centrallines for the reading of the chapters $2-4$ of the Proslogion. We shall attempt to point out both the significance and the achievement of that interpretation as a contribution to the historiografy of the anselmian thought.

- KEYWORDS: Anselm; the ontological argument; existence; essence.

\section{Referências bibliográficas}

BARTH, K. S. Anselme, Fides Quaerens Intellectum. La preuve de l'existence de Dieu. Trad.

J. Corrèze. Genève: Labor et Fides, 1985.

BOUILLARD, H. Karl Barth. Paris: Aubier, 1957. 3t.

. La preuve de Dieu dans le Proslogion et son interprétation par Karl Barth, in Spicilegium Beccense. CONGRES INTERNATIONAL DU IX CENTENAIRE DE L'ARRIVÉE D'ANSELME AU BEC, 1. Paris: Vrin, 1959.

DELHOUGNE, H. L'argument ontologique est-il philosophique ou théologique? Examen critique de la position de Barth. Revue des Sciences Religieuses, p.42-63, 1979.

DESCARTES, R. Premières réponses. Textes établis par F. Alquié. Paris: Garnier, 1967, t.II. (Coll. Oeuvres Philosophiques).

GILSON, E. Christianisme et philosophie. Paris: Vrin, 1949.

HEGEL, G. W. F. Les preuves de l'existence de Dieu. Trad. H. Niel. Paris: Aubier, 1947.

KANT, I. Crítica da razão pura. Trad. Santos. Lisboa: Fundação Calouste Gulbenkian, 1985.

PALIARD, J. Prière et dialectique. Dieu Vivant, n.6, p.51-70.

SANCTUS ANSELMI Cantuariensis Archiepiscopi. Opera Omnia ad fidem codicum recensuit F. S. Schmitt. Thomas Nelson et Filius, 1946-51.

VANNI-ROVIGHI, S. S. Anselmo e la filosofia del sec. XI. Milano: Fratelli Bocca, 1947. VIGNAUX, P. Saint Anselme, Barth et au-delà. In: Les quatres fleuves. Paris: Seuil, 1973. 